\title{
Quantidade de Transposição do Líquido Pulverizado sobre Palha de Cana-de-Açúcar com Pontas de Pulverização Tipo LEQUE E CONE ${ }^{1}$
}

\author{
Transposition Amount of Liquid Sprayed on Sugarcane Straw using Fan and Cone Type Nozzles
}

\author{
CONTIERO, R.L. ${ }^{2}$, FRANCISCHINI, A.C. ${ }^{3}$, SANTOS, G. ${ }^{3}$, RUVER, A. ${ }^{3}$ e CURIONE, C. ${ }^{4}$
}

\begin{abstract}
RESUMO - A colheita da cana-crua promove aumento de restos culturais de cobertura morta sobre o solo. Esse novo componente altera a dinâmica de infestação de plantas daninhas e atua também como barreira física e química à ação dos herbicidas. Visando melhorar a qualidade da deposição dos herbicidas no solo, objetivou-se neste trabalho avaliar a eficiência das pontas de pulverização e sua capacidade de transposição sobre a palha de cana-deaçúcar. O experimento foi instalado em Maringá-PR. O delineamento experimental utilizado foi o inteiramente casualizado, em esquema fatorial $8 \times 7$, sendo oito pontas de pulverização (AD 110 02, ADIA 110 02, TT 110 02, TTIA 110 02, CV-IA02, MAG 2, ST 02 e TJ60 110 02) e sete quantidades de palha $\left(0,1,2,4,6,8\right.$ e $\left.10 \mathrm{t} \mathrm{ha}^{-1}\right)$. Assim, observou-se que grandes quantidades de palha reduzem a quantidade do líquido pulverizado que foi depositado na superficie coletora. As pontas de pulverização leque antideriva (AD 110 02) e cone vazio com indução de ar (CV-IA 02) foram as mais eficientes.
\end{abstract}

Palavras-chave: cobertura morta, gotas, herbicida.

ABSTRACT - Raw sugarcane harvest promotes an increase in crop residues of mulch on the soil. This new component changes the dynamics of weed infestation, also acting as a physical and chemical barrier against the action of herbicides. To improve the quality of herbicide deposition on the soil, this study aimed to evaluate the efficiency of spray nozzles and their transposition capacity on sugarcane straw. The experiment was conducted in Maringá- $P R$, in a completely randomized design, using a factorial scheme $8 \times 7$, with 8 nozzles (AD 110 02, ADIA 110 02, TT 110 02, TTIA 110 02, CV IA 02, MAG 2, ST 02 and TJ60 110) and 7 increasing amounts of straw $\left(0,1,2,4,6,8\right.$ and 10 tha $\left.{ }^{1}\right)$. It was observed that large quantities of straw reduce the amount of liquid sprayed and deposited on the collecting surface. The spray nozzles anti-drift fan model (AD 110 02) and empty cone with air induction (CV-IA O2) were the most efficient.

Keywords: mulch, drops, herbicide.

\section{INTRODUÇÃO}

A produção do etanol brasileiro é capaz de substituir a gasolina com vantagens ambientais significativas, pois evita a emissão de gás carbônico (2,6-1.7 $\left.\mathrm{t} \mathrm{CO}_{2} \mathrm{~m}^{3}\right)$ e produz energia renovável em mais de 8,3 vezes a energia dos insumos fósseis utilizados, calculados com base no ciclo de vida do etanol (Macedo et al., 2007).

Recebido para publicação em 5.4.2011 e aprovado em 13.10.2011.

2 Professor, Doutor, Dep. de Agronomia da Universidade Estadual de Maringá - UEM, Av. Colombo n. 5790, 87020-9000 MaringáPR; ${ }^{3}$ Engo-Agro ${ }^{\circ}$, Mestrando(a) do Curso de Pós-Graduação em Agronomia na área de Proteção de Plantas, NAPD/UEM; ${ }^{4}$ EngenheiraAgrônoma. 
Para diminuir os impactos ambientais na produção sucroalcooleira, foi aprovado o Decreto no 47.700, de $11 / 2 / 2003$, que regulamenta a Lei no 11.241 de 19/9/2002 e proíbe a queimada da cana-de-açúcar no Estado de São Paulo, segundo o esquema de restrições legais progressivas até o ano de 2021, em áreas com possibilidade de mecanização total da colheita, e até 2031, nas demais áreas (Timossi \& Durigan, 2006).

Com a proibição das queimadas inicia-se um novo ciclo, marcado pelo uso de novas tecnologias. Nesse caso, a colheita da cana é realizada de forma mecanizada, também conhecida como cana-crua, acumulando no solo uma espessa camada de palha, que pode atingir uma quantidade de mais de $20 \mathrm{t} \mathrm{ha}^{-1}$ (Santos et al., 2009).

A palha pode alterar o estabelecimento e o crescimento de plantas daninhas em áreas cultivadas, bem como reduzir a amplitude térmica do solo, interceptando comprimentos de luz necessários à germinação de algumas espécies infestantes, formando uma barreira física à emergência de plantas daninhas, além dos possiveis efeitos alelopáticos, que inibem a germinação e/ou crescimento inicial dessas plantas.

Assim, o acúmulo de cobertura morta e as mudanças químicas, físicas e biológicas no solo podem selecionar a comunidade infestante, suprimindo ou estimulando a germinação de plantas daninhas importantes. No entanto, estudos realizados por Martins et al. (1999) demonstram que a cobertura morta na superficie do solo pode não causar efeito supressor emalgumas espécies de plantas daninhas, como Euphorbia heterophylla e Ipomoea grandifolia, surgindo então como plantasproblema na cultura da cana.

Portanto, a manutenção da palha sobre a superficie do solo pode, simultaneamente, reduzir o potencial de infestação de algumas plantas daninhas, não interferir em outras e, ainda, dificultar o desempenho dos herbicidas, pela barreira fisica propiciada pela cobertura morta na superficie do solo.

Após um herbicida ser aplicado sobre a palha, é interceptado pela superficie desta e torna-se vulnerável à volatilização e/ou fotólise, até ser lixiviado para o solo (Locke \& Bryson, 1997). Lamoreaux et al. (1993) explicam que o transporte de herbicidas da palha para o solo é dependente da capacidade da palha de cobrir o solo e reter esses herbicidas, das características físico-químicas do herbicida, bem como do período em que a área permanece sem chuva após a aplicação.

A fim de justificar o aumento das doses dos herbicidas aplicados em pré-emergência no plantio direto, muitos produtores alegam que, devido à cobertura morta, os produtos não atingem o solo, provocando um controle ineficiente das plantas infestantes. Dessa maneira, muitos estudos estão sendo feitos na área da tecnologia de aplicação com o intuito de aprimorar técnicas na utilização de bicos de pulverização e volumes de aplicação, a fim de obter melhora na deposição e transposição dos produtos pela palhada.

Em razão da falta de estudos sobre o potencial de pontas de pulverização para herbicidas aplicados em pré-emergência no sistema de plantio direto e também na cana-crua, realizou-se este ensaio visando avaliar o desempenho de diferentes modelos de pontas de pulverização na transposição de calda através de crescentes quantidades de palha de canade-açúcar (Saccharum spp.).

\section{MATERIAL E MÉTODOS}

O experimento foi conduzido nas dependências da Universidade Estadual de Maringá, nos meses de outubro a novembro de 2009.

O delineamento experimental utilizado foi o inteiramente casualizado, em esquema fatorial $8 \times 7$, sendo oito pontas de pulverização e sete quantidades crescentes de palha. Os tratamentos foram constituídos pelo monitoramento do traçador corante Azul Brilhante (FDC-1) a 3.000 ppm. A pressão, o volume de aplicação, o tamanho e diâmetro das gotas, bem como as pontas de pulverização utilizadas, encontram-se na Figura 1. Nota-se que as pressões usadas foram selecionadas de acordo com a ponta de pulverização para atingir a vazão em torno de $200 \mathrm{~L} \mathrm{ha}^{-1}$, simulando assim as aplicações realizadas em campo.

Em todos os tratamentos, foi avaliada a quantidade de deposição da pulverização que 
Tabela 1 - Pontas de pulverização utilizadas, bem como o modelo, pressão, volume de aplicação, velocidade e de aplicação, tamanho de gotas e diâmetro

\begin{tabular}{|c|c|c|c|c|}
\hline Ponta de Pulverização & $\begin{array}{c}\text { Pressão } \\
\left(\mathrm{lbf} \mathrm{pol}^{-2}\right)\end{array}$ & $\begin{array}{c}\text { Volume de aplicação } \\
\left(\mathrm{L} \mathrm{ha}^{-1}\right)\end{array}$ & Tamanho de gotas & $\begin{array}{c}\text { Diâmetro de gotas } \\
(\mu \mathrm{m})\end{array}$ \\
\hline AD 11002 & 70 & 208 & Médias & $201 \mathrm{a} 400$ \\
\hline ADIA 110 02 & 70 & 208 & Muito grossas & $>600$ \\
\hline TT 110 02 & 70 & 208 & Médias & 201 a 400 \\
\hline TTIA 110 02 & 70 & 204 & Muito grossas & $>600$ \\
\hline ST 02 & 70 & 208 & Médias & 201 a 400 \\
\hline TJ60 110 02 & 70 & 205 & Médias & 201 a 400 \\
\hline MAG-2 & 150 & 200 & Muito finas & 51 a 100 \\
\hline CV-IA 02 & 150 & 208 & Médias & 201 a 400 \\
\hline
\end{tabular}

conseguiu transpor as quantidades de $0,1,2$, 4, 6, 8 e 10 t ha $^{-1}$ de palha de cana-de-açúcar (Saccahrum spp.). As palhas foram coletadas em áreas de produção após a colheita da cultura. Posteriormente foram submetidas à secagem em estufa de circulação forçada de ar a $60^{\circ} \mathrm{C}$, até obter seu peso constante.

As unidades experimentais foram representadas por recipientes (caixas tipo gerbox), com área de superficie de $0,0121 \mathrm{~m}^{2}$, que receberam papel absorvente nas laterais, para impedir o escorrimento do líquido pulverizado, e coletores plásticos posicionados no fundo de cada unidade experimental, com o objetivo de coletar apenas a quantidade de produto que conseguiu transpor a palhada. Após esse procedimento, as diferentes quantidades de palha de cana-de-açucar foram posicionadas sobre a superficie coletora.

A aplicação foi realizada através de pulverizador costal pressurizado a $\mathrm{CO}_{2}$ com pressão constante, equipado com barra de pulverização posicionada a $0,5 \mathrm{~m}$ de altura da palhada $\mathrm{e}$ munida de quatro pontas de pulverização, com espaçamento de $0,5 \mathrm{~m}$ entre bicos, trabalhando em velocidade de $6,0 \mathrm{~km} \mathrm{~h}^{-1}$, para todos os tratamentos. No momento das aplicações a temperatura era de $24^{\circ} \mathrm{C}$, e a umidade relativa do ar, de $65 \%$, com velocidade do vento de aproximadamente $1,9 \mathrm{~km} \mathrm{~h}^{-1}$.

A recuperação e posterior quantificação da calda de pulverização que transpassou a palha foram efetuadas ao final da aplicação dos tratamentos, após a secagem do pulverizado depositado nos respectivos coletores (15 minutos). As palhas foram descartadas e os coletores lavados com $30 \mathrm{~mL}$ de água destilada, dentro de outro recipiente plástico previamente limpo.

A determinação da concentração $\left(\mathrm{mg} \mathrm{L}^{-1}\right)$ recuperada do traçador nas soluções obtidas com a lavagem dos coletores foi feita por meio de curvas-padrão de linearidade, utilizandose soluções com concentrações conhecidas do corante FDC 1, em água destilada. Essas soluções foram analisadas juntamente com as amostras, na densidade óptica (absorbância) de $630 \mathrm{~nm}$, em espectrofotômetro de UV visível.

Os dados foram submetidos à análise de variância e estudos de regressão, sendo as médias comparadas entre si por meio do teste de agrupamento de Scott-Knott a 5\% de probabilidade.

\section{RESULTADOS E DISCUSSÃO}

Comparando a quantidade de deposição do produto traçador que transpassou as diferentes quantidades de palha com as pontas de pulverização AD 11002 , ADIA 11002 , TT 110 02, TTIA 110 02, CV-IA 02 MAG 2, ST 02 e TJ60 110 02, pode-se demonstrar que todos os tratamentos com a presença da palha $(1,2$, 4, 6, 8 e 10 tha $^{-1}$ ) apresentaram volume de deposição inversamente proporcional, isto é, à medida que houve aumento da quantidade da palha sobre a superficie coletora, houve diminuição progressiva do líquido que transpassou a mesma e chegou à superficie de coleta (Tabela 2 e Figura 1). 
Tabela 2 - Quantidade de deposição da pulverização $\left(\mu \mathrm{L} \mathrm{cm}^{-2}\right)$ que atingiu os coletores situados abaixo dos fragmentos, em quantidade crescente da palha de cana-de-açúcar

\begin{tabular}{|c|c|c|c|c|c|c|c|}
\hline \multirow{2}{*}{ Tratamento } & \multicolumn{7}{|c|}{ Quantidade de palha $\left(\mathrm{t} \mathrm{ha}^{-1}\right)$} \\
\hline & 0 & 1 & 2 & 4 & 6 & 8 & 10 \\
\hline AD110002 & $0,005804 \mathrm{Ca}$ & $0,002719 \mathrm{Bb}$ & $0,001492 \mathrm{Ac}$ & $0,001100 \mathrm{Ad}$ & $0,000819 \mathrm{Ad}$ & $0,000870 \mathrm{Ad}$ & $0,000768 \mathrm{Ad}$ \\
\hline ADIA11002 & $0,003076 \mathrm{Fa}$ & $0,001423 \mathrm{Db}$ & $0,000845 \mathrm{Bc}$ & $0,000560 \mathrm{Bc}$ & $0,000498 \mathrm{Ac}$ & $0,000505 \mathrm{Bc}$ & $0,000455 \mathrm{Ac}$ \\
\hline TT11002 & $0,002615 \mathrm{Ga}$ & $0,001165 \mathrm{Db}$ & $0,000675 \mathrm{Bc}$ & $0,000551 \mathrm{Bc}$ & $0,000488 \mathrm{Ac}$ & $0,000499 \mathrm{Bc}$ & $0,000430 \mathrm{Ac}$ \\
\hline TTIA11002 & $0,004252 \mathrm{Ea}$ & $0,002030 \mathrm{Cb}$ & $0,000764 \mathrm{Bc}$ & $0,000280 \mathrm{Bd}$ & $0,000176 \mathrm{Bd}$ & $0,000206 \mathrm{Bd}$ & $0,000146 \mathrm{Ad}$ \\
\hline CV-IA02 & $0,006338 \mathrm{Ba}$ & $0,002407 \mathrm{Bb}$ & $0,001348 \mathrm{Ac}$ & $0,000859 \mathrm{Ad}$ & $0,000690 \mathrm{Ad}$ & $0,000852 \mathrm{Ad}$ & $0,000586 \mathrm{Ad}$ \\
\hline MAG 2 & $0,004991 \mathrm{Da}$ & $0,001563 \mathrm{Db}$ & $0,000667 \mathrm{Bc}$ & $0,000319 \mathrm{Bc}$ & $0,000162 \mathrm{Bc}$ & $0,000178 \mathrm{Bc}$ & $0,000122 \mathrm{Ac}$ \\
\hline ST 02 & $0,008335 \mathrm{Aa}$ & $0,003416 \mathrm{Ab}$ & $0,001230 \mathrm{Ac}$ & $0,000785 \mathrm{Ac}$ & $0,000377 \mathrm{Bd}$ & $0,000319 \mathrm{Bd}$ & $0,000335 \mathrm{Ad}$ \\
\hline TJ60 11002 & $0,004062 \mathrm{Ea}$ & $0,001589 \mathrm{Db}$ & $0,000648 \mathrm{Bc}$ & $0,000366 \mathrm{Bc}$ & $0,000172 \mathrm{Bc}$ & $0,000240 \mathrm{Bc}$ & $0,000195 \mathrm{Ac}$ \\
\hline Pontas (Po): & \multicolumn{7}{|c|}{$64,406^{*}$} \\
\hline Palha (Pa): & \multicolumn{7}{|c|}{$866,160^{*}$} \\
\hline Po x Pa: & \multicolumn{7}{|c|}{$18,280^{*}$} \\
\hline $\mathrm{CV}(\%):$ & \multicolumn{7}{|c|}{36,14} \\
\hline
\end{tabular}

Médias seguidas de mesma letra maiúscula, na coluna, e minúscula, na linha, não diferem entre si a 5\% de probabilidade pelo teste de ScottKnott.

Dessa forma, este experimento permite entender que diferentes quantidades de cobertura morta afetam a transposição de herbicidas aplicados sobre a palhada, de maneira a ser uma barreira no controle químico das plantas infestantes. Do mesmo modo, alguns autores têm estudado sobre lixiviação e ação dos herbicidas através da cobertura morta; de acordo com Azania et al. (2004), grandes quantidades de cobertura vegetal sobre o solo (acima de $15 \mathrm{t} \mathrm{ha}^{-1}$ ), têm o potencial de reter o herbicida imazapic, especialmente sob periodos de seca prolongada.

Sabendo que a cobertura vegetal se torna uma barreira a herbicidas aplicados, é interessante analisar a quantidade de líquido pulverizado que transpassa a palhada por diferentes tipos de pontas, selecionando assim as que promovem maior deposição do líquido traçador na superficie coletora.

Dessa forma, verifica-se na Tabela 2 que, em presença de $1 \mathrm{t} \mathrm{ha}^{-1}$ de cobertura morta, a ponta ST 02 apresentou maior volume depositado na superficie analisada, sendo superior ao das demais pontas testadas. Pontas como a modelo leque antideriva (AD 110 02) e cone vazio com indução de ar (CV-IA 02), responsáveis pela produção de gotas médias, apresentaram transposição semelhante entre si e superior à das pontas TTIA 110 02, ADIA 110 02, TT 110 02, MAG-2 e TJ60 11002.
À medida que aumentou a quantidade de palha sobre a superfície, a diferença de deposição da calda foi sendo reduzida entre as pontas de pulverização, agrupando-as em apenas duas categorias: as que obtiveram maior e menor transposição. Monquero et al. (2007) observaram significativa redução de controle de alguns herbicidas quando estes foram aplicados sobre grande quantidade de palha no solo, principalmente do diuron + hexazinone e imazapic, possivelmente devido a predisposição à retenção pela palha, não atravessando em quantidade suficiente para o controle de Euphorbia heterophylla.

As pontas de pulverização leque antideriva (AD 110 02), cone vazio com indução de ar (CV-IA 02) e leque com inclinação frontal (ST 02), todas responsáveis por produzir gotas médias (201 a $400 \mu \mathrm{m}$ ), quando utilizadas em aplicações tanto sobre 2 t ha ${ }^{-1}$ quanto sobre $4 \mathrm{t} \mathrm{ha}^{-1}$ de cobertura de cana-de-açúcar, mostraram transposição superior à das demais pontas testadas (ADIA 11002 , TT 110 02, TTIA 110 02, MAG 2 e TJ 60110 02).

Quando em presença de $6 \mathrm{t} \mathrm{ha}^{-1}$, a transposição da calda de pulverização começa a ser dificultada, diminuindo drasticamente a quantidade de produto aplicado sobre a cobertura morta que chega à superficie coletora. Nesse caso, a maior foi 
obtida pelas pontas AD 11002 , ADIA 11002 TT 11002 e CV-IA 11002.

Nota-se ainda que essa deposição é maior quando são utilizados pontas que produzem gotas maiores que $200 \mu \mathrm{m}$, isto é, gotas médias a grossas, provavelmente devido ao fato de serem gotas mais pesadas, que conseguem transpor a palhada e chegar à superficie coletora com mais facilidade, e, ainda, não serem levadas pelo vento ou volatilizadas tão rapidamente, como acontece com gotas finas e muito finas.

Com a presença de palhada mais densa sobre a superficie coletora, a transposição do liquido pulverizado reduz drasticamente. Assim, pontas de pulverização como a leque antideriva ( $\mathrm{AD} 110$ 02) e a cone vazio com indução de ar (CV-IA 02), em aplicações realizadas sobre $8 \mathrm{t} \mathrm{ha}^{-1}$ de palha de cana, alcançaram resultados superiores aos das demais pontas utilizadas para aspergir a solução traçadora.

Nesse patamar, pode-se perceber que, com presença de $8 \mathrm{t}^{\text {ha }} \mathrm{H}^{-1}$ de palha sobre a superficie coletora, há redução do líquido depositado de 69,01 e $64,60 \%$ nas aplicações realizadas com
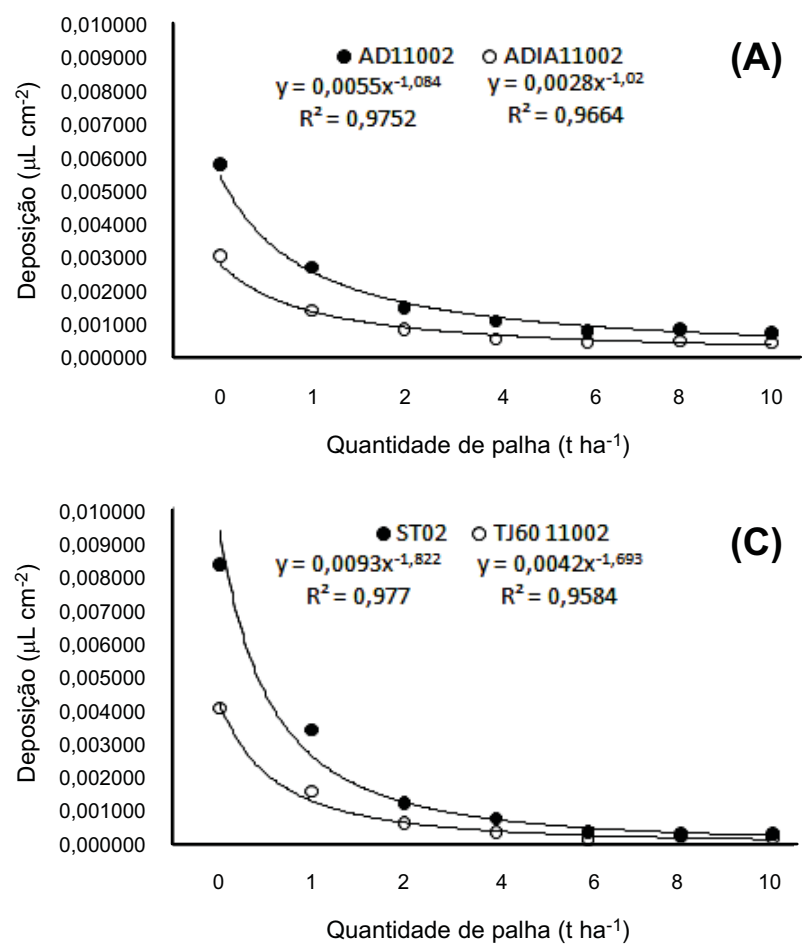

as pontas $\mathrm{AD} 11002$ e CV-IA 02, respectivamente - pontas que sobressaíram às demais, quando comparadas à deposição obtida sobre $1 \mathrm{t} \mathrm{ha}^{-1}$-, o que evidencia um problema em aplicações com grandes quantidades de cobertura morta, tornando dificil a escolha de pontas de pulverização.

$\mathrm{Na}$ presença de $10 \mathrm{t} \mathrm{ha}^{-1}$ de restos culturais, nenhuma ponta sobressaiu, tendo todas alcançado volume de aplicação semelhante entre si.

Para melhor visualização e confirmação dos dados apresentados na Tabela 2, foram realizadas análises de regressão da deposição da pulverização entre pontas simples ou com tecnologiade indução de ar e jato duplo ou com jato de inclinação frontal. Nesse caso, foram comparadas: ponta leque antideriva (AD 110 02) $\mathrm{x}$ ponta leque antideriva com indução de ar (ADIA 110 02); ponta leque jato plano de grande ângulo (TT 110 02) x ponta leque jato plano de grande ângulo com indução de ar; ponta cone vazio (MAG-02) x ponta cone vazio com indução de ar (CV-IA); e ponta leque com inclinação frontal (ST-02) x ponta leque jato plano comum duplo (TJ60 110 02) (Figura 1).
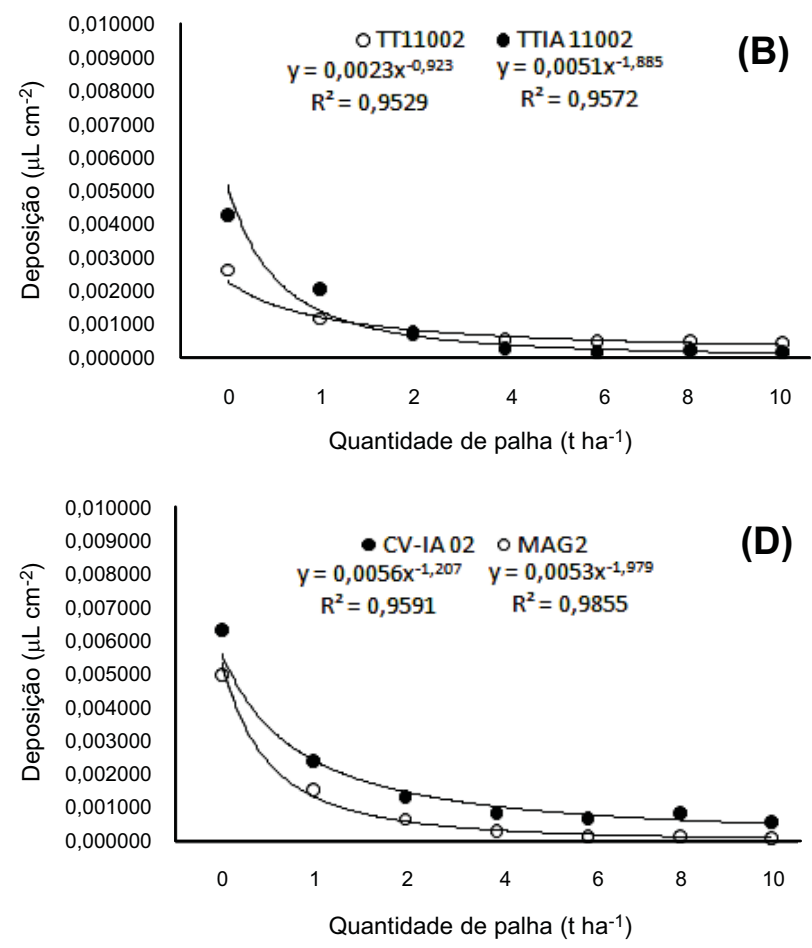

Figura 1 - Deposição de pulverização entre pontas de características semelhantes $\left(\mu \mathrm{L} \mathrm{cm}{ }^{-2}\right)$. 
Na Figura 1A, comparando-se o volume de deposição proporcionado pela ponta leque antideriva (AD 11002 ) com a deposição obtida pela ponta leque antideriva com indução de ar (ADIA 110 02), nota-se que a primeira ponta alcançou maior transposição pela palhada em todos os tratamentos testados $\left(1,2,4,6,8\right.$ e $\left.10 \mathrm{t}^{\text {ha }}{ }^{1}\right)$. A mesma tendência pode ser observada na Figura 1C, para as pontas ST 02 e TJ60 11002.

Esses resultados reforçam a premissa de que gotas médias conseguem atingir alvos mais internos e penetrar a palhada do que gotas grossas, como aquelas produzidas pela ponta ADIA 110 02, que, por apresentar tecnologia de indução de ar, acaba por produzir gotas maiores do que a das pontas sem indução de ar.

Quanto às pontas TTIA 11002 e TT 11002 só foram observadas diferenças entre elas até $1 \mathrm{t} \mathrm{ha}^{-1}$.

Em relação às aplicações realizadas com pontas modelo cone vazio, na Figura 1D, observou-se tendência de CV-IA 02 obter maior deposição em relação à ponta MAG 2, provavelmente pelo fato de as gotas muito finas produzidas por esta última estarem sujeitas a maior deriva e volatilização.

As pontas tipo cone vazio usam pressões de trabalho que geram em torno de 200 a $1.000 \mathrm{kPa}$, produzindo dessa maneira gotas menores do que as produzidas por pontas tipo leque. Com a obtenção de gotas de diâmetro pequeno, tem-se como consequência maior densidade de gotas depositadas sobre o alvo para um mesmo volume de aplicação (Cross et al., 2001) e, em contrapartida, um aumento de deriva. Esses resultados indicam que grandes quantidades de cobertura morta, apesar de contribuírem com as propriedades e estrutura do solo, podem se tornar uma barreira física e por vezes até química contra os herbicidas utilizados em pré-emergência na cultura, dificultando assim o controle de algumas plantas daninhas.

Conclui-se que a transposição do produto traçador aplicado sobre a palha de cana-de- açúcar é inversamente proporcional ao aumento da quantidade de palha, ou seja, com o aumento da quantidade da cobertura morta depositada sobre a superficie, há redução na transposição do produto traçador pela palha.

Houve, portanto, diferença significativa entre as pontas de pulverização quando utilizadas até $8 \mathrm{t} \mathrm{ha}^{-1}$ de palha de cana-de-açúcar, sendo as pontas AD 11002 e CV IA 02 superiores às demais.

\section{LITERATURA CITADA}

AZANIA, C. A. M. et al. Seletividade do imazapic para dois cultivares de amendoim (Arachis hypogaea) cultivados na ausência e na presença de palha de cana-de-açúcar.

Planta Daninha, v. 22, n. 1, p. 145-150, 2004.

CROSS, J. V. et al. Spray deposits and losses in different sized apple trees from an axial fan orchard sprayer: Effects of spray quality. Crop Protec., v. 20, n. 2, p. 4, 2001.

LAMOREAUX, R. J. et al. Efficacy of dimethenamid, metolachlor and encapsulated alachlor in soil covered with crop residue. Bringhton Crop Protec. Conf. - Weeds, v. 3, n. 1, p. 1015-1020, 1993.

LOCKE, M. A.; BRYSON, C. T. Herbicide-soil interaction in reduced tillage and plant residue management systems. Weed Sci., v. 45, n. 2, p. 307-20, 1997.

MACEDO, I. C. et al. Green house gases emissions in the production and use of ethanol from sugarcane in Brazil: The 2005/2006 averages and a prediction for 2020. Biomass Bioen., v. 32, n. 7, p. 582-595, 2007.

MARTINS, D. et al. Emergência em campo de dicotiledôneas infestantes em solo coberto com palha de cana-de-açúcar. Planta Daninha, v. 17, n. 1, p. 151-161, 1999.

MONQUERO, P. A. et al. Eficácia de herbicidas em diferentes quantidades de palha de cana-de-açúcar no controle de Euphorbia heterophylla. Planta Daninha, v. 25, n. 3, p. 613-619, 2007.

SANTOS, G. et al. Eficácia e seletividade do herbicida imazapic isolado ou associado a outros herbicidas aplicado com e sem cobertura de palha de cana-de-açúcar. R. Bras. Herbic., v. 8, n. 3, p. 75-84, 2009.

TIMOSSI, P. C.; DURIGAN, J. C. Manejo de convolvuláceas em dois cultivares de soja semeada diretamente sob palha residual de cana crua. Planta Daninha, v. 24, n. 1, p. 91-98, 2006. 